\section{UJMM

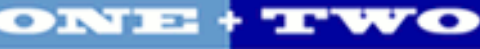

Volume 3 | 2011 Spring

\section{Undergraduate Journal of Mathematical}

Modeling: One + Two

2011

\title{
Correlation Among Different Variables and Life Expectancy
}

June Liu

University of South Florida

Advisors:

Arcadii Grinshpan, Mathematics and Statistics

Andrei Chugunov, Fortis College: Medical Sciences

Problem Suggested By: Andrei Chugunov

Follow this and additional works at: https://digitalcommons.usf.edu/ujmm

Part of the Mathematics Commons

UJMM is an open access journal, free to authors and readers, and relies on your support:

Donate Now

\section{Recommended Citation}

Liu, June (2011) "Correlation Among Different Variables and Life Expectancy," Undergraduate Journal of Mathematical Modeling: One + Two: Vol. 3: Iss. 2, Article 2.

DOI: http://dx.doi.org/10.5038/2326-3652.3.2.2

Available at: https://digitalcommons.usf.edu/ujmm/vol3/iss2/2 


\title{
Correlation Among Different Variables and Life Expectancy
}

\author{
Abstract \\ expectancy. \\ Keywords \\ Life expectancy, Heart Rate, Blood Pressure, Weight \\ Creative Commons License \\ (c) (i) (9)
}

The purpose of this project is to show how heart rate, blood pressure, and weight of different species correlate with their life expectancy. We perform graphical analysis and compute Pearson's ProductMoment Correlation Coefficient to show that the heart rate has the highest degree of correlation with life

This work is licensed under a Creative Commons Attribution-Noncommercial-Share Alike 4.0 License. 


\section{TABLE OF CONTENTS}

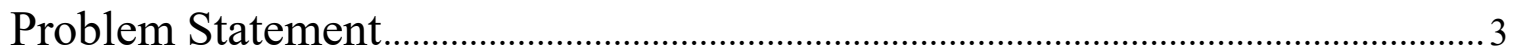

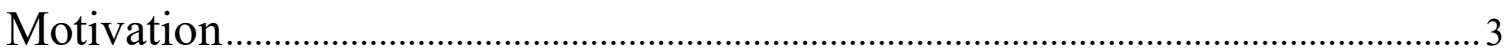

Mathematical Description and Solution Approach ...................................................

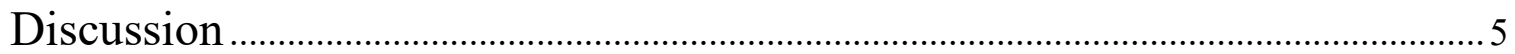

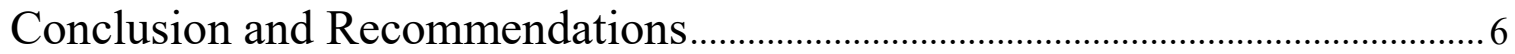

Nomenclature

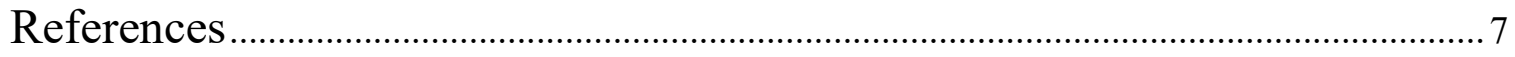

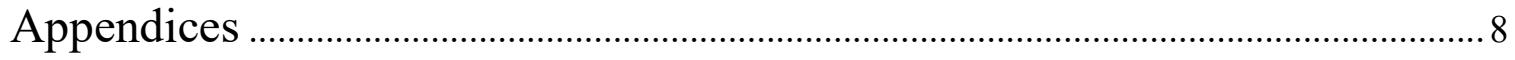




\section{PROBLEM STATEMENT}

Find variables that strongly correlate with life expectancy.

\section{MOTIVATION}

The secret to longevity continues to elude humanity to this day. Despite all the advances in medicine, cardiovascular disease, obesity, and abnormal blood pressure continue to be serious and life-shortening conditions. Finding variables that strongly correlate with life expectancy may help us to understand which aspects of these and other conditions present the highest health risk. This, in turn, may help us to design treatments that would have the most effect in prolonging patient's life span.

Recent studies show that a lower heart rate (known as bradycardia) in otherwise normal heart is beneficial because it prevents the heart from overworking and increases efficiency. Athletes, for example, are known to have a lower resting heart rate (see Table 1).

\begin{tabular}{|c|c|c|}
\hline Human & Heart Rate (per min) & Life Expectancy (years) \\
\hline \multirow{2}{*}{$\begin{array}{c}\text { Bradycardia } \\
\text { (no symptoms) }\end{array}$} & 40 & 123.5 \\
\cline { 2 - 3 } & 50 & 98.9 \\
\hline \multirow{2}{*}{ Athletes } & 60 & 82.4 \\
\cline { 2 - 3 } & 68 & 72.7 \\
\cline { 2 - 3 } Average & 70 & 70.6 \\
\cline { 2 - 3 } & 80 & 61.8 \\
\hline Tachycardia & 84 & 58.9 \\
\hline
\end{tabular}

Table 1: Life Expectancy estimations based on heart rate (calculated by (CSG)). 
Blood Pressure is the pressure exerted by blood on the blood vessels. Normal blood pressure for humans falls between 90 to $140 \mathrm{mmHg}$. Blood pressure lower than $90 \mathrm{mmHg}$ (known as hypotension) is considered abnormally low. Abnormally high blood pressure, or hypertension, is a pressure above $140 \mathrm{mmHg}$. Unlike heart rate, both high and low blood pressure negatively affects health and may results in cardio-vascular disease, stroke, and even death (Franco, Peeters and Bonneux).

Obesity, which runs rampant in the United States, is shown to take years off the affected individual's life unless proper diet and exercise are employed. Studies are based on an individual's body mass index (BMI), which is calculated by dividing a person's weight (in kilograms) by the square of a person's height (in meters). Oxford University researchers found that moderate obesity shortens life expectancy by almost 3 years whereas a severe obesity can shorten the life expectancy by up to 10 years (ScienceDaily).

Instead of concentrating solely on humans, we determine whether weight, heart rate, or blood pressure has strong correlation with life expectancy using the data describing multiple species.

\section{MATHEMATICAL DESCRIPTION AND SOLUTION APPROACH}

We use Pearson's Product-Moment Correlation Coefficient (PPMCC) to determine whether specie's weight, heart rate, blood pressure have strong correlation with its lifespan. PPMCC is given by

$$
r_{x y}=\frac{\sum x_{i} y_{i}-n \bar{x} \bar{y}}{n s_{x} s_{y}}=\frac{n \sum x_{i} y_{i}-\sum x_{i} \sum y_{i}}{\sqrt{n \sum x_{i}^{2}-\left(\sum x_{i}\right)^{2}} \sqrt{n \sum y_{i}^{2}-\left(\sum y_{i}\right)^{2}}}
$$


where $x_{i}$ is the $i$ th $x$ score, $\bar{x}$ is the mean of $x$, and $s_{x}$ is the standard deviation of $x\left(y_{i}, \bar{y}\right.$, and $s_{y}$ are defined symmetrically).

It turns out that PPMCC is always between -1 and 1 . A correlation coefficient of 1 indicates a strong direct linear relationship; a coefficient of -1 indicates a strong inverse linear relationship; and a coefficient of 0 indicates that there is no correlation between the two variables. We compute PPMCC for the heart rate, blood pressure, and weight to understand which of the three has the strongest correlation with the lifespan.

Our calculations of PPMCC are based on the data from Table 3 (see also Figure 1) and summarized in Table 2.

\begin{tabular}{|l|c|c|c|c|c|c|c|}
\hline Variable & $n$ & $\sum x$ & $\sum y$ & $\sum x^{2}$ & $\sum y^{2}$ & $\sum x y$ & $r_{x y}$ \\
\hline Heart rate & 20 & 708 & 2541 & 65295 & 684137 & 33879 & -0.44 \\
\hline Blood pressure & 18 & 707 & 2231 & 65295 & 336721 & 88491 & -0.16 \\
\hline Weight & 20 & 708 & 129470 & 65295 & 14428679504 & 10750497 & 0.25 \\
\hline
\end{tabular}

Table 2: PPMCC of heart rate, blood pressure, and weight versus lifespan.

\section{DISCUSSION}

Pearson's Product-Moment Correlation Coefficient (PPMCC) can be interpreted as follows (Cohen):

\begin{tabular}{|l|l|l|}
\hline Correlation & Negative & Positive \\
\hline None & -0.09 to 0.00 & 0.00 to 0.09 \\
\hline Small & -0.30 to -0.10 & 0.10 to 0.30 \\
\hline Medium & -0.50 to -0.30 & 0.30 to 0.50 \\
\hline Large & -1.00 to -0.50 & 0.50 to 1.00 \\
\hline
\end{tabular}


According to our calculations, there is a medium correlation $(-0.44)$ between life expectancy and heart rate. According to Figure 1, as life span increases, heart rate decreases. Two extremes are giant tortoises (200 year lifespan, 6 bpm heart rate) and common houseflies (1 month lifespan, $300 \mathrm{bpm}$ heart rate).

There is a small correlation between blood pressure and life expectancy $(-0.16)$. Blood pressure, however, depends on the environment and organism's life style, so more precise correlation estimate could be obtained by factoring these parameters into the analysis.

The correlation between life expectancy and weight $(0.25)$ is also small. Weight and life expectancy are related directly: as the weight of an organism increases, so does its life expectancy. Outliers such as whales and tortoises, however, suggest that there may be no true correlation between these variables.

From the three analyzed variables, the heart rate has the highest correlation with life expectancy.

\section{CONCLUSION AND RECOMMENDATIONS}

Based on the analysis presented above, we conclude that heart rate has the highest correlation with life expectancy. It is recommended that individuals who wish to prolong their life should lead active lifestyle. Aerobic exercises are probably the most beneficial. In addition, daily exercise and a healthy life style will decrease the likelihood of obesity and normalize blood pressure. 


\section{NOMENCLATURE}

\begin{tabular}{|c|l|}
\hline Symbol & Description \\
\hline$r_{x y}$ & Pearson's Product-Moment Correlation Coefficient between variables $x$ and $y$ \\
\hline $\bar{x}$ & the mean of variable $x$ \\
\hline$s_{x}$ & the standard deviation of variable $x$ \\
\hline
\end{tabular}

\section{REFERENCES}

Cohen, Jacob. Statistical Power Analysis for the Behavioral Sciences. New York: Academic, 1977.

CSG, Computer Support Group, Inc. Life Expectancy Estimator by Heart Rate. n.d. 9 May 2011

$<$ http://www.csgnetwork.com/avglifeexpfromhr.html $>$.

Franco, Oscar H., et al. "Blood Pressure in Adulthood and Life Expectancy With Cardiovascular Disease in Men and Women." Hypertension (2005): 46:280-286.

ScienceDaily. "Moderate Obesity Takes Years Off Life Expectancy." 19 March 2009. http://www.sciencedaily.com/.<http://www.sciencedaily.com/releases/2009/03/090319224823.ht $\mathrm{m}>$.

Watkins, Thayer. "Animal Longevity and Scale." 09 May 2011. San José State University. $<$ http://www.sjsu.edu/faculty/watkins/longevity.htm>. 


\section{APPENDIX-TABLES}

\begin{tabular}{|c|c|c|c|c|}
\hline Organism & $\begin{array}{c}\text { Heart Rate } \\
(\mathbf{b p m})\end{array}$ & $\begin{array}{c}\text { Blood Pressure } \\
(\mathbf{m m H g})\end{array}$ & $\begin{array}{c}\text { Weight } \\
\text { (kilograms) }\end{array}$ & $\begin{array}{c}\text { Lifespan } \\
\text { (years) }\end{array}$ \\
\hline $\begin{array}{c}\text { Giant } \\
\text { Tortoise }\end{array}$ & 6 & 150 & 300 & 200 \\
\hline Crocodile & 24 & 60 & 800 & 45 \\
\hline Human & 70 & 120 & 90 & 75 \\
\hline Elephant & 30 & 145 & 5000 & 70 \\
\hline Whale & 20 & 26 & 120000 & 85 \\
\hline Giraffe & 65 & 300 & 900 & 25 \\
\hline Cow & 65 & 157 & 800 & 22 \\
\hline Horse & 44 & 120 & 1200 & 40 \\
\hline Sheep & 75 & 90 & 57 & 10 \\
\hline Medium Dog & 90 & 150 & 5 & 13 \\
\hline Cat & 150 & 129 & 2 & 15 \\
\hline Snake & 45 & 55 & .100 & 10 \\
\hline Mouse & 600 & 111 & .020 & 2 \\
\hline Rabbit & 205 & 120 & 1 & 10 \\
\hline Monkey & 192 & 140 & 5 & 20 \\
\hline Guinea Pig & 240 & 60 & .1 & 8 \\
\hline Grizzly Bear & 70 & 170 & 160 & 32 \\
\hline Pig & 70 & 128 & 150 & 25 \\
\hline Housefly & 300 & -- & .000012 & .08 \\
\hline Daphnia & 180 & -- & .000000163 & .50 \\
\hline
\end{tabular}

Table 3: Mean heart rate, blood pressure, weight, and lifespan of various organisms (blood pressures of housefly and daphnia were omitted since no data could be found) (Watkins). 


\section{APPENDIX-FIGURES}
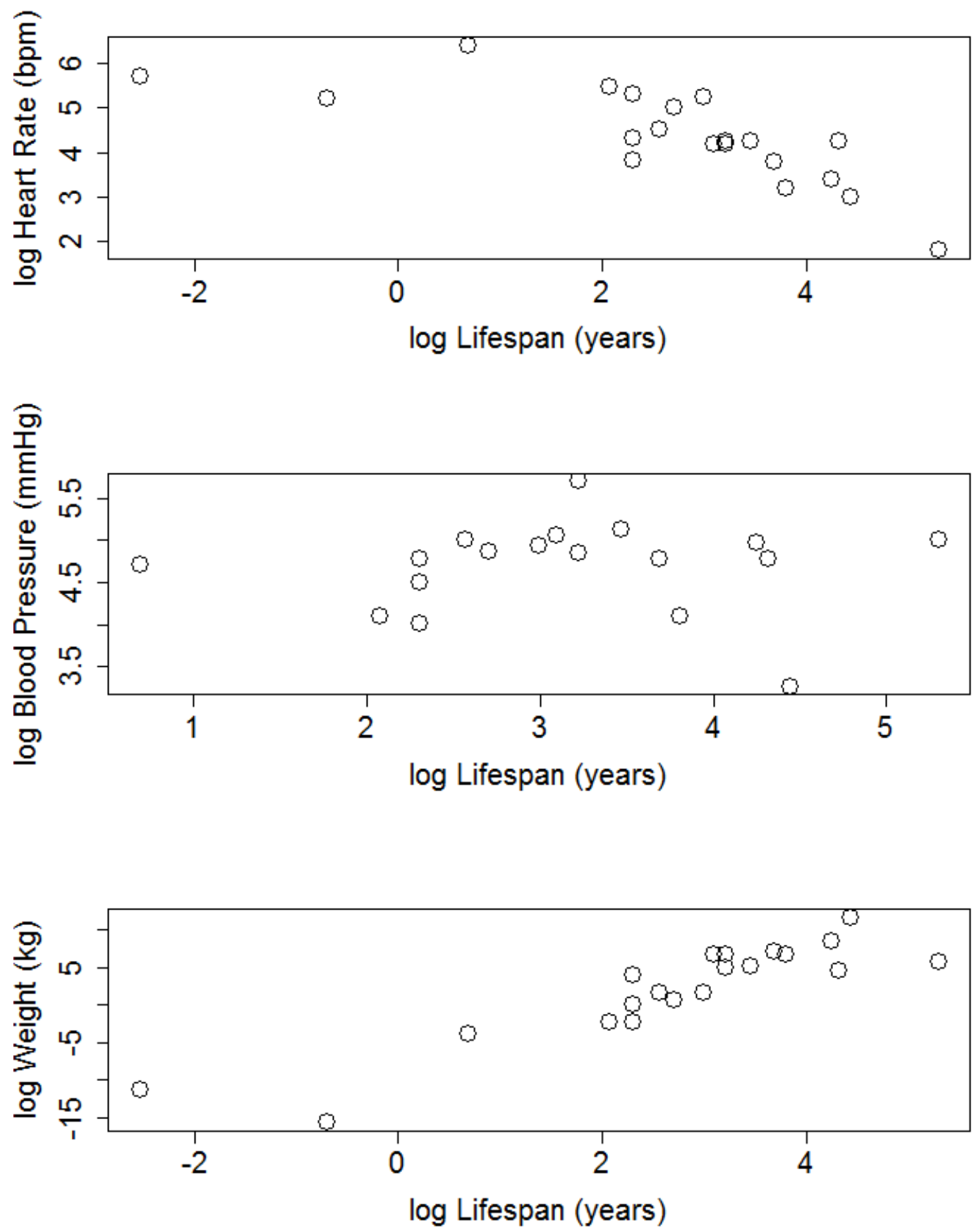

Figure 1: Log-log plot of the data from Table 3. 